\title{
HONEYCOMB LUNG AND XANTHOMATOSIS
}

\author{
BY \\ A. M. MACDONALD and ROBERT A. SHANKS \\ From the Department of Child Health, University of Glasgow, and the Royal Hospital for Sick Children, Yorkhill, \\ Glasgow
}

(RECEIVED FOR PUBLICATION DECEMBER 8, 1953)

In 1927 an unusual radiographic appearance of the lungs in which a peculiar meshwork was seen throughout both lung fields was described. The course of the associated illness was rapid, beginning with a paroxysmal cough and dyspnoea, and progressing to severe respiratory distress, cyanosis and death. At necropsy the radiographic appearance was seen to be due to a multitude of small alveolar cysts. There was some fibrosis and also what was described as an unusual type of granulation tissue with giant cells. To this condition the name of fibrocystic disease of the lungs was given (Kerley, 1927; Kerley, Shore and Young, 1927). In the following year a similar case was reported in which the condition was shown to be due to a generalized xanthomatosis (Rowland, 1928). Later, Berg and Vejlens (1939) and Berg and Zachrisson (1941) and de Fine Licht (1942) described the same condition associated with tuberous sclerosis.

Although the interest stimulated by this curious radiographic appearance is comparatively recent, the necropsy findings of a lung honeycombed with small cysts has long been recognized, especially in children. Sharkey described two children, aged 2 and 4 years, in 1894. Tooth (1897) recorded the condition in a baby of 18 months, Fletcher (1901) in a girl aged $3 \frac{1}{2}$ and Bernstein (1905) and Hebb and Bernstein (1905) each in a girl aged 3 years. The morbid anatomy and histology of these cases is described in great detail, and comment is made upon the cellular infiltration of the cavity walls and the presence of giant-cells so characteristic of the cases to be described (Bernstein, 1905). It seems more than likely that, had radiography been available, a similar appearance would have been seen. Honeycomb lung (Fig. 1), the name given by Oswald and Parkinson (1949), is now a well recognized if rare radiographic finding and is easily distinguishable from other disseminated lung lesions such as miliary tuberculosis, pulmonary haemosiderosis and the pneumoconioses (Kerley, 1951). It is also distinguished from multiple lung cysts, usually con- fined to a part of a lung, by the uniformity of size and distribution of the component cysts.

This lung lesion has been reported in association with xanthomatosis, biliary cirrhosis, diabetes insipidus and tuberous sclerosis. A number of cases also have been recorded in which the cause has been obscure; in a few such cases a congenital anomaly has been postulated (Oswald, 1952). Children are not infrequently affected and of the 16 cases reviewed by Oswald and Parkinson (1949) seven were

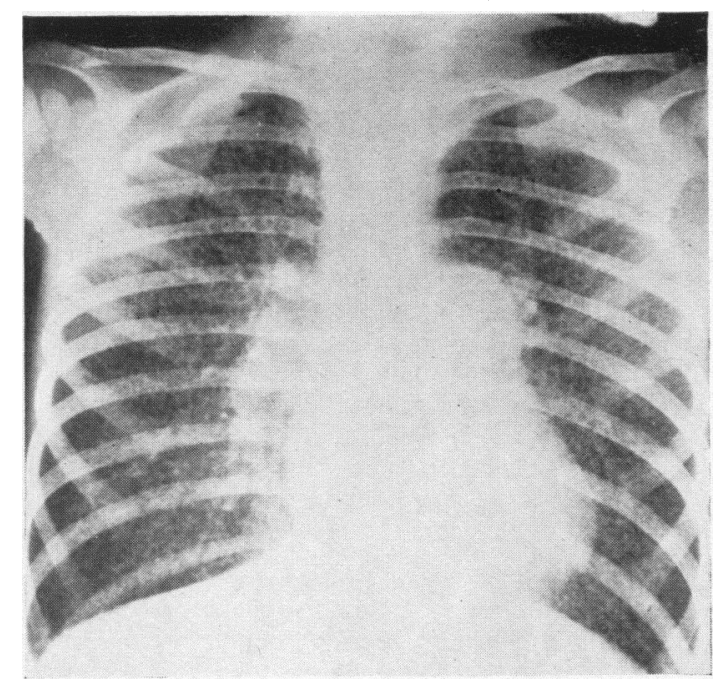

FIG. 1.-Radiograph of the chest showing diffuse honeycomb appearance and hilar enlargement in Case 3.

children. Three of these had xanthomatosis, two had biliary cirrhosis, while in the remaining two the diagnosis was obscure.

The purpose of this paper is to report three cases seen in the Royal Hospital for Sick Children, Glasgow, during the past five years, together with four further cases culled from the records of the hospital in which the diagnosis was made in retrospect on re-examination of the histological 
material, the point of interest being that the underlying cause in each case was found to be generalized xanthomatosis.

\section{Case Reports}

Case 1. A girl aged 2 years and 9 months was admitted on January 15, 1948, with the diagnosis of Ollier's disease and miliary tuberculosis. She was an only child and her father had open tuberculosis. She had an uneventful early history apart from the chondrodystrophy which had been diagnosed at the age of 16 months. In October, 1947, she became fretful and listless, began to lose weight, and on April 26, 1947, she was admitted with a "snowstorm' lung and tuberculous meningitis. This diagnosis was confirmed by culture and guinea-pig inoculation from the spinal fluid. She was treated with streptomycin and showed considerable improvement until March 5, 1948 , when she suddenly deteriorated, becoming intensely dyspnoeic and cyanosed. She died on March 8, 1948. At necropsy there was seen in addition to the tuberculous meningitis and miliary tuberculosis, which were showing signs of resolution, a typical honeycomb lung with unequivocal histological evidence of a generalized xanthomatosis.

Case 2. A boy aged 19 months was admitted on September 20, 1948, with the complaint of increasing jaundice and dyspnoea. He was the youngest in a family of six; there was no relevant family history. His early history was unremarkable except for bronchopneumonia at the age of 5 weeks; this was followed by an attack of diarrhoea. In April, 1948 (at the age of 1 year), vomiting, anorexia and failure to gain weight developed; he soon became jaundiced and the urine was bile stained and his stools pale grey. Dyspnoea and a paroxysmal cough then appeared. The liver was palpable two fingerbreadths below the costal margin but there was otherwise no abnormality on clinical examination. A radiograph of the chest showed the characteristic appearance of honeycomb lurig and of the skull that of Hand-SchüllerChristian disease. His condition deteriorated rapidly and he died on August 19, 1948. At necropsy he was found to have a diffuse xanthomatosis with multiple, thinwalled cysts of the lung. The liver also was xanthomatous.

Case 3. A girl, aged 2 years and 10 months, was admitted on February 2, 1952, with the complaint of a spasmodic cough and pyrexia, and dyspnoea with occasional cyanosis. She was the youngest of four; there was no relevant family history. Her early history was unremarkable except that she was rather slow to thrive. In February, 1952, she developed a spasmodic cough which became very severe and was later accompanied by cyanosis.

On admission she was a thin, wasted child with sordes on the lips. Her respirations were rapid and rather distressed but there was no clinical abnormality detected in the chest. The liver was palpable four fingerbreadths below the costal margin. A radiograph of the chest showed a well marked honeycomb appearance (Fig. 1). Her condition deteriorated rapidly and she died on March 1, 1952. At necropsy there was a generalized xanthomatosis with multiple, thin-walled cysts of the lungs and xanthomatous involvement of the liver.

The records of four similar cases in which 'multiple alveolar cysts' had been found post mortem were examined.

Case 4. A girl aged 2 years and 2 months was admitted on November 13, 1920, with a complaint of severe dyspnoea, cough and cyanosis. She was the sixth child in a family of seven; there was no relevant family history. Her early history was uneventful and she was well until November 4, 1920, when she developed a cough and dyspnoea. On admission she was slightly cyanosed and showed marked respiratory distress. Abundant fine râles were heard in the chest; the $\mathrm{x}$-ray appearance was described as a 'discrete mottling' and ascribed to miliary tuberculosis. The child died on November 20, 1920, and at necropsy there was a conspicuously honeycombed lung which on re-examination of the histological material was seen to be xanthomatous.

Case 5. A boy aged 3 years and 2 months was first admitted on May 28, 1926, with a complaint of cough and dyspnoea. The younger of a family of two, he was healthy at birth and throve and developed normally. There was no relevant family history. Apart from measles he had no previous illnesses and was well until April 4, 1926, when he developed a cough, respiratory distress and fever. Bronchopneumonia was diagnosed. On admission he was found to have a liver enlarged two and a half fingerbreadths below the costal margin; abundant fine râles were heard over both lungs. The x-ray appearance of the lungs was described as a 'snow-storm lung' and diagnosed as miliary tuberculosis. He remained reasonably well and was dismissed home. Thereafter his condition remained unchanged until in March, 1927, when he became intensely dyspnoeic and cyanosed. He was re-admitted and died on March 28, 1927. At necropsy there was a honeycomb lung associated with generalized xanthomatosis with fibrosis of the liver and pancreas.

Case 6. A girl aged 17 months was admitted on November 26, 1930, with the complaint of abdominal swelling and progressive dyspnoea. She was the younger of two and there was no relevant family history. She throve and developed normally and was well until two months before admission when she became listless and increasingly dyspnoeic. Her parents also noticed an increasing abdominal swelling. On admission she was found to have enlargement of both liver and spleen but no signs referable to the lungs. She died on December 17, 1930 , and at necropsy was found to have a honeycomb lung associated with enlargement of both liver and spleen. Re-examination of the histological material available demonstrated a generalized xanthomatosis with early portal cirrhosis of the liver.

Case 7. A boy aged 1 year was admitted on June 7, 1934, with a history of spasmodic cough and loss of weight. He was an only child and there was no relevant family history. He was healthy at birth but was slow to thrive and after the first few weeks of life had bouts of 
coughing. Following an illness described as pneumonia at the age of 5 months, his cough became more severe and spasmodic. On admission a radiograph of the chest was reported as showing multiple cavities, and congenital bronchiolectasis was diagnosed. He was re-admitted on December 22, 1934, with intense dyspnoea, fever and cyanosis, and died on January 7, 1935. At necropsy multiple lung cysts were found and re-examination of the histological material showed a secondarily infected honeycomb lung.

\section{Pathology}

With minor exceptions the pathological findings in these cases have been so similar that a general description will serve.

To the naked eye the lungs appeared voluminous and mottled, with paler and more solid areas alternating with translucent cystic areas under the smooth pleura. On section the uniform size and distribution of the cysts gave the characteristic honeycomb appearance (Fig. 2). The diameter of these cysts varied around a mean of $0.25 \mathrm{~cm}$.

Histology. The histological picture was as consistent as the naked-eye appearance. The cysts appeared to be distensions of alveoli, atria and respiratory bronchioles. Involvement of larger bronchioles, as indicated by the presence of muscle in the cyst walls, could not be detected. Septa and alveolar walls were irregularly infiltrated with histio-

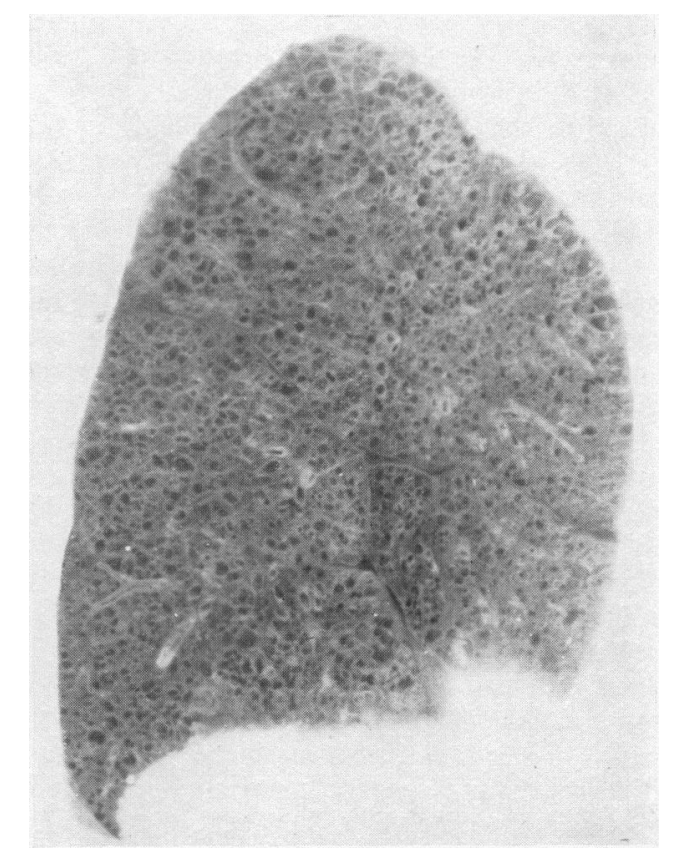

FIG. 2.-A vertical section of the right lung of the same case as in Fig. 1. The general cystic condition of the lung is shown. cytes. These histiocytes were densely packed polygonal cells with oval or indented nuclei and

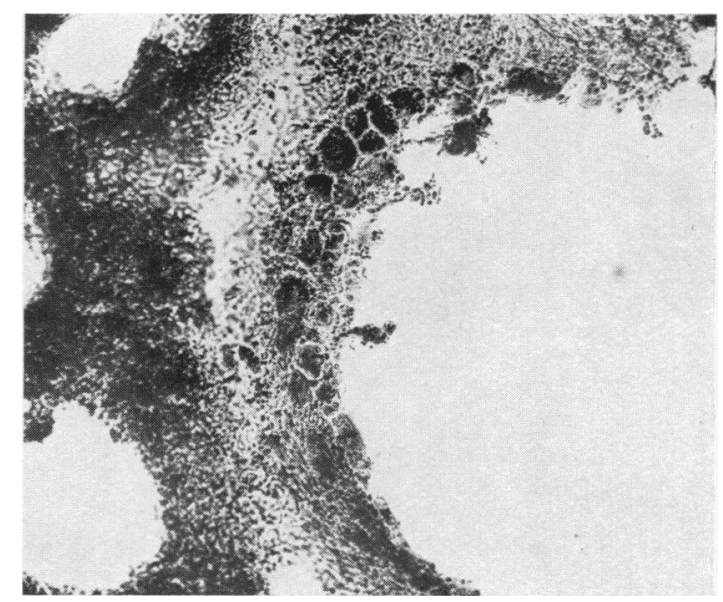

FIG. 3.-Photomicrograph of a cyst showing fat-laden giant cells in the wall. Xanthomatous tissue is present adjacent to this cyst with intracellular fat appearing dark. Sudan III and IV $\times 45$.

cytoplasm often filled with lipoid material. These lipoid-containing histiocytes constitute the xanthoma cell characteristic of Hand-Schüller-Christian disease and allied disorders. Aggregations of this xanthomatous tissue were also seen forming discrete tubercles. These were easily distinguishable from those of tuberculosis by the absence of an endothelial reaction and necrosis, but the presence of giant cells, although scanty, and of eosinophils, might suggest a diagnosis of Hodgkin's disease (Fig. 3). Where tissue preserved in formalin was still available, frozen sections were stained with a mixture of Sudan III and IV. Lipoid was found in every case but could not be related in amount to the intensity of the histiocytic reaction. In some instances the cysts were lined with lipoid-filled giant-cells (Fig. 4). Weigert's stain demonstrated the destruction of the elastica in the alveolar and atrial walls where histiocytic infiltration had occurred. The mechanism of cyst production seems to be a combination of this destruction of elastic tissue and obstruction of the respiratory bronchiole by aggregations of xanthomatous tissue.

In only five cases was liver tissue available for examination, and in four of these, xanthomatous infiltration of the portal tracts with obstruction of the bile ducts was found. In some sections merely a portal cirrhosis could be seen, not in itself diagnostic of xanthomatosis. Lipoid could be demonstrated in the macrophages lining the large ducts and in the Küpfer cells. Pancreatic fibrosis was noted in one 
case while in the lymph nodes the loss of follicular definition together with the presence of giant-cells

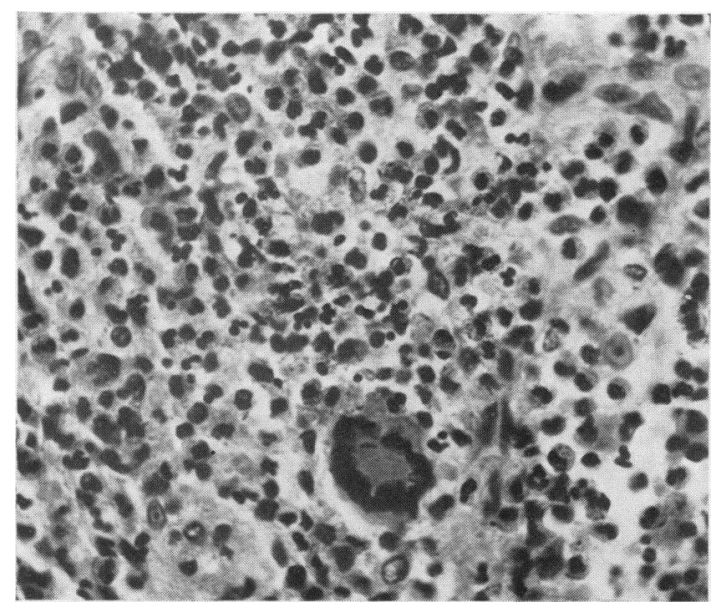

Fig. 4.-A xanthomatous mass to indicate the variety of cells which may be found in such tissue. There is a giant-cell surrounded by histiocytes, round cells and eosinophils. Haematoxylin and eosin $\times 150$.

and eosinophils was suggestive of Hodgkin's disease. In the spleen there was an ill-defined histiocytic infiltration with scanty giant-like cells and eosinophils.

\section{Discussion}

The clinical picture of paroxysmal cough and dyspnoea in combination with the radiographic appearance of honeycomb lung is so striking and so immediately recognizable as to arouse one's interest in its pathogenesis in spite of its undoubted rarity.

Clinically there is a strong resemblance to idiopathic pulmonary haemosiderosis as described by Wyllie, Sheldon, Bodian and Barlow (1948) and this, indeed, was our initial diagnosis in the second case. Pulmonary haemosiderosis, however, is associated with attacks of haemolysis which a haematological investigation will serve to demonstrate and, moreover, does not show the honeycombing characteristic of pulmonary xanthomatosis (Gellis, Reinhold and Green, 1953).

The diagnosis of xanthomatosis in our cases may perhaps require some elaboration. The classification of the reticulo-endothelioses has recently received considerable attention, and there is now some evidence for regarding Hand-Schüller-Christian disease, eosinophilic granuloma of bone and Letterer-Siwe disease as merely variants of the same disease (Wallgren, 1940; Farber, 1941; Jaffe and
Lichtenstein, 1944); intermediate forms occur comprising a complete range of reticuloses between Hand-Schüller-Christian disease on the one hand and Letterer-Siwe disease on the other. In all these conditions a consistent cytological picture prevails, namely an infiltration of histiocytes with scanty giant-cells and a variable number of eosinophils. The term xanthomatosis implying, as it does, the presence of lipoid, would seem to be inadequate for such a range of disorders. There are, however, cogent arguments against this view of the unity of all reticuloses (Siwe, 1949). It is to be expected that there would be a similarity between different disorders of the same system and this in itself cannot be held to justify the assumption that they have a common pathogenesis.

As far as our series is concerned lipoid was demonstrable in every case. The amount of stainable fat, however, bore no relation to the intensity of the histiocytic reaction nor was it to be found in every aggregation of histiocytes. Thus in certain areas the histological picture might resemble a non-lipoid reticulosis, the lipoid only being demonstrable on more searching examination.

In restricting the concept of xanthomatosis for the purposes of this communication to that of a lipoid reticulosis, we are supported by the fact that in all the cases of honeycomb lung cited, in which there was an associated xanthomatosis, it was a lipoid reticulosis that was described. It seems likely, moreover, that Letterer-Siwe disease would be too acute and eosinophilic granuloma of bone too localized to be responsible for such a lung lesion.

Nevertheless, in view of the variable histological picture encountered in this condition it seems possible that some errors in diagnosis have occurred. We have already indicated that the presence of giant-cells and eosinophils may simulate Hodgkin's disease and that special fat staining may be necessary for correct diagnosis. In the case of honeycomb lung reported by Douglas and Claireaux (1953) it would be instructive to know whether a lipoid reticulosis had been excluded by this means.

In most of the recorded cases of honeycomb lung in childhood the pathogenesis has been ascribed to xanthomatosis, biliary cirrhosis or tuberous sclerosis. In addition a few cases of obscure origin have been recorded in which there was no evidence of any of these conditions. Berg and Zachrisson (1941) record one and Oswald and Parkinson (1949) record two such cases: each had in addition, symptoms of diabetes insipidus. From the foregoing it seems likely that there is some link between these and a generalized xanthomatosis and that some recorded cases of obscure origin also have this basis. It is 
tempting to suppose that the cases of biliary cirrhosis in which a honeycomb lung was found were similar to our own cases and that they, too, were xanthomatous. However that may be, in each of our seven cases, representing the sole yield of more than 30 years' necropsies in an active teaching hospital, the diagnosis has been shown to be xanthomatosis. It seems justifiable, therefore, to suggest that in childhood at least the clinico-radiographic picture of paroxysmal dyspnoea and honeycomb lung should be regarded as most likely due to a generalized xanthomatosis. Tuberous sclerosis, the other possible cause, is an even rarer condition than pulmonary xanthomatosis and can be recognized from the stigmata of the disease.

Although biopsy of a lymph node will in many cases provide the diagnosis, the clinical course of xanthomatosis is such that death will not be long delayed and post-mortem examination will reveal the nature of the disease.

\section{Summary}

Seven cases of honeycomb lung are described in which the causative condition was found to be a generalized xanthomatosis. It is suggested that in childhood xanthomatosis is the likeliest cause of this clinical and radiographic picture.

We are grateful to Professor Stanley Graham and Dr. J. H. Hutchison, O.B.E., for permission to report these cases.

REFERFNCES

Berg. G. and Vejlens, G. (1939). Acta paediat., Uppsala, 26, 16.

and Zachrisson, C. G. (1941). Acta. radiol. Stockh., 22, 425.

Bernstein, J. M. (1905). Trans. path. Soc. Lond., 56, 330.

Douglas, D. M. and Claireaux, A. E. (1953). Archives of Disease in Childhood, 28, 222.

Farber, S. (1941). Amer. J. Path., 17, 625.

Fine Licht, E. de (1942). Acta radiol. Stockh., 23, 151

Fletcher, H. M. (1901). Trans. path. Soc. Lond., 52, 193.

Gellis, S. S., Reinhold, J. L. D. and Green, S. (1953). Amer. J. Dis. Child., 85, 303 .

Hebb, R. G. and Bernstein, J. M. (1905). Westminster Hosp. Rep., 14, 309.

Jaffe, H. L. and Lichtenstein, L. (1944). Arch. Path. Chicago, 37, 99. Kerley, P. (1927). Brit. J. Radiol. (B.I.R. Sect.), 32, 245.

Kerley, (1951). Textbook of X-ray Diagnosis by British Authors. 2nd ed. ed. Shanks, S. C. and Kerley, P., vol. 2, p. 309. London. ed. Shanks, S. C. and Kerley, P., vol. 2, p. 309. London
Shore, L. R. and Young, W. A. (1927). Lancet, 2, 699.

Oswald, N. (1952). In Diseases of the Chest, ed. Marshall, G. and Perry, K. M. A., vol. 2, p. 200 . London.

- and Parkinson, T. (1949). Quart. J. Med., 18, 1.

Rowland, R. S. (1928). Arch. intern. Med., 42, 611 .

Sharkey, S. J. (1894). St Thom. Hosp. Rep., 22, 33.

Siwe, S. (1949). Advanc. Pediat., 4, 117.

Tooth, H. H. (1897). Trans. path. Soc. Lond., 48, 30.

Wallgren, A. (1940). Amer. J. Dis. Child., 60, 471.

Wyllie, W. G., Sheldon, W., Bodian, M. and Barlow, A. (1948). Quart. J. Med., 17, 25 